\title{
Mixed emotions: the contribution of alexithymia to the emotional symptoms of autism
}

\author{
G Bird ${ }^{1,2}$ and R Cook $^{3}$
}

It is widely accepted that autism is associated with disordered emotion processing and, in particular, with deficits of emotional reciprocity such as impaired emotion recognition and reduced empathy. However, a close examination of the literature reveals wide heterogeneity within the autistic population with respect to emotional competence. Here we argue that, where observed, emotional impairments are due to alexithymia-a condition that frequently co-occurs with autism-rather than a feature of autism per se. Alexithymia is a condition characterized by a reduced ability to identify and describe one's own emotion, but which results in reduced empathy and an impaired ability to recognize the emotions of others. We briefly review studies of emotion processing in alexithymia, and in autism, before describing a recent series of studies directly testing this 'alexithymia hypothesis'. If found to be correct, the alexithymia hypothesis has wide-reaching implications for the study of autism, and how we might best support subgroups of autistic individuals with, and without, accompanying alexithymia. Finally, we note the presence of elevated rates of alexithymia, and inconsistent reports of emotional impairments, in eating disorders, schizophrenia, substance abuse, Parkinson's Disease, multiple sclerosis and anxiety disorders. We speculate that examining the contribution of alexithymia to the emotional symptoms of these disorders may bear fruit in the same way that it is starting to do in autism. Translational Psychiatry (2013) 3, e285; doi:10.1038/tp.2013.61; published online 23 July 2013

\section{Introduction}

Autism is a disorder characterized principally by social deficits: two of three main diagnostic features-impaired communication and reciprocal social interaction-lie within the social domain. Although global emotional deficits are not currently a diagnostic feature of autism, problems of emotion processing, such as a lack of empathy and impaired recognition of emotion in others, are considered to be diagnostic markers of the condition. ${ }^{1,2}$ Despite the existing consensus that impairments of emotion processing are a feature of the autistic phenotype, empirical testing has yielded surprisingly equivocal results. In the present paper we argue that, where observed, emotional difficulties within the autistic population are actually attributable to alexithymia-a condition that frequently co-occurs with autism-rather than a feature of autism per se.

Alexithymia is a subclinical condition characterized by difficulties in identifying and describing one's own emotional state. ${ }^{3}$ For example, individuals with alexithymia might know that they are experiencing an emotion, but be unaware whether that emotion is sadness, anger or fear. Although the incidence of alexithymia in the typical population is estimated at $10 \%$, elevated levels of alexithymia are seen in a number of disorders such as anorexia nervosa, substance abuse and post-traumatic stress disorder. ${ }^{4}$ The incidence of alexithymia is particularly high in the autistic population, with between 40 and $65 \%$ of adults with autism meeting criteria. ${ }^{6,7}$ (We use the terms 'autistics' and 'individuals with autism' to refer to the population of individuals with an autism spectrum condition as these terms are most favored by that population. ${ }^{5}$ ) Alexithymia has also been shown to be part of the 'Broader Autism Phenotype', ${ }^{8}$ the cluster of autism-like traits observed in parents of autistic children. Despite their frequent cooccurrence, alexithymia and autism are independent constructs. Alexithymia is neither necessary nor sufficient for an autism diagnosis, nor is it universal among autistic individuals. Conversely, many individuals show severe degrees of alexithymia without demonstrating autistic symptoms.

\section{The emotional symptoms of autism}

Difficulties in the emotional domain have been considered a feature of autism since the first cases reported by Kanner ${ }^{9}$ and Asperger. ${ }^{10}$ Reduced 'emotional reciprocity' is still considered to be a clinically significant indicator of autism, ${ }^{2}$ and some have argued that global emotional difficulties are a core feature of autism. ${ }^{11,12}$ However, a close reading of the literature reveals that the empirical evidence in support of this claim is strikingly inconsistent. ${ }^{13-15}$ More consistent is the substantial variability within the population of individuals with autism; some individuals are clearly impaired, whereas other autistic individuals perform at normal levels.

Emotion recognition. Many empirical findings have been published consistent with the hypothesis that individuals with

\footnotetext{
${ }^{1}$ MRC Social, Genetic \& Developmental Psychiatry Centre, Institute of Psychiatry, Kings College London, London, UK; ${ }^{2}$ Institute of Cognitive Neuroscience, University College London, London, UK and ${ }^{3}$ Department of Psychology, City University London, London, UK

Correspondence: Dr G Bird, MRC Social, Genetic \& Developmental Psychiatry Centre, Institute of Psychiatry P080, London, SE5 8AF, UK.

E-mail: geoff.bird@kcl.ac.uk

Keywords: alexithymia; autism; emotions; empathy; expressions; heterogeneity

Received 19 February 2013; revised 2 May 2013; accepted 25 May 2013
} 
autism find it harder to recognize, interpret and describe emotional stimuli. Several studies have reported that autistic individuals show poor recognition of emotional facial expressions, in particular those with negative valence, relative to matched controls. ${ }^{16-19}$ Some autistic individuals also seem to be impaired at recognizing the emotional valence of verbal and nonverbal vocal cues, ${ }^{20,21}$ body movements ${ }^{21-23}$ and describing the emotional content of music. ${ }^{24}$ Moreover, some individuals with autism have difficulties matching the emotional cues conveyed by faces, voices and body postures across domains. ${ }^{12,25}$ Complimentary neuroimaging results have been reported showing atypical responses in regions of the face-processing network when autistic individuals view emotional expressions. ${ }^{26-28}$

However, the picture is strikingly equivocal. Numerous studies have found no evidence of facial emotion recognition deficits in autism. ${ }^{29-31} \mathrm{~A}$ quantitative meta-analysis of the impact of autism on facial emotion recognition indicated a small effect size from a very mixed literature. ${ }^{15}$ Independent qualitative reviews have concluded 'behavioral studies are only slightly more likely to find facial emotion recognition deficits in autism than not' (Harms et al. ${ }^{13}$ p. 317) and 'most studies fail to show any deficits at all in the perception of simple emotions by children with [high-functioning autistic spectrum disorder]' (Begeer et al. ${ }^{14}$ p. 348) Several studies have also reported intact recognition of vocal affect, ${ }^{32-34}$ including one conducted with a large sample $(N=99)$ of autistic adolescents and matched controls. ${ }^{33}$ Various factors have been cited as possible causes of this heterogeneity, including sample demographics-for example, potential differences due to the use of children/adults and the use of high/low-functioning autistic participants-and methodologies - for example, the nature of the control groups used, the types of emotional stimuli and the recognition procedures vary widely throughout the literature. ${ }^{13,15}$

Empathy. It is frequently asserted that individuals with autism not only have difficulties recognizing emotions, but also lack emotional empathy. ${ }^{35-40}$ Defining empathy is no trivial matter, but our working definition here will be that empathy occurs when the perception of another's emotional state causes the empathizer to experience that state. This definition distinguishes empathy from Theory of Mind ${ }^{41}$ (also known as 'cognitive empathy') that refers to the ability to represent, but not necessarily share, another's mental state. (Several authors would argue that this definition of empathy is not sufficient; that in order for full empathy to be demonstrated, a degree of self-other distinction is necessary (in contrast to emotional contagion). Here we are referring only to the process by which recognition of another's emotional state causes that state to be experienced by the self, rather than to self-other distinction that may or may not be affected by alexithymia.)

Consistent with this characterization, several studies have found that individuals with autism score lower on self-report empathy questionnaires including the Empathy Quotient ${ }^{37,42}$ and the Interpersonal Reactivity Index of empathy (IRI). ${ }^{38,43}$ In addition, when presented with vignettes describing other children's emotional experiences, some children with autism report less empathy with the characters described. ${ }^{44}$ It has also been reported that some individuals with autism show less corticospinal excitability when observing a painful stimulus being applied to another person, ${ }^{40}$ and a weaker tendency to imitate the emotional facial expressions of others. $^{39}$ Studies using functional neuroimaging have found atypical neural responses when autistic individuals view emotional stimuli in the brain regions thought to mediate empathy $^{45,46}$ and in the mirror neuron system ${ }^{47}$ that may mediate imitation of emotional facial expression (although imitation and activation of the mirror neuron system are conceptually distinct from empathy, in the special case of emotional expressions, imitation may lead to emotional contagion and ultimately empathy).

However, the evidence for an empathy deficit in autism is again surprisingly mixed. ${ }^{48}$ Several studies have found no group differences in empathy using self-report measures. ${ }^{49,50}$ Moreover, reports of group differences on self-report measures of empathy often obscure the fact that a significant proportion of those with autism, and their families, report equal or super-normal degrees of empathy. ${ }^{51}$ Some authors have found that autistic children demonstrate entirely typical emotional responses during social interactions and to recorded emotional expressions of others. ${ }^{52}$ Several studies also report perfectly intact automatic tendencies to imitate emotional facial expressions in individuals with autism ${ }^{53}$ and increased electromyographic signals-an index of covert imitative motor activity - to vocal and facial emotion. ${ }^{54}$ Finally, several neuroimaging studies have failed to find differential mirror neuron system activation when autistic participants view emotional facial expressions. ${ }^{28,55}$

\section{The alexithymia hypothesis}

The alexithymia hypothesis suggests that, where observed, the 'emotional symptoms of autism' are in fact due to the greater proportion of individuals with severe alexithymia in the autistic population. Alexithymia is characterized by difficulties in identifying and describing one's own emotional state. ${ }^{3}$ Nevertheless, a considerable body of evidence suggests that individuals with high degrees of alexithymia also have difficulties in recognizing emotional facial expressions, particularly those with negative valence. ${ }^{56-61}$ Moreover, it is also well established that alexithymia is associated with reduced empathy. ${ }^{62-66}$ Such findings accord well with the growing consensus that the mechanisms responsible for our subjective experience of emotions are recruited when recognizing the same emotions in others. ${ }^{67,68}$

Alexithymia is thought to be the product of developmental dysfunction of, or reduced connectivity between, limbic structures, including the anterior insula (AI) and anterior cingulate cortex (ACC); ${ }^{69,70}$ the regions implicated in the subjective experience of emotion, affect recognition and empathy. ${ }^{70,71}$ Early studies suggested that both of these regions failed to show the typical modulation of cerebral blood flow when alexithymic participants viewed angry faces. ${ }^{72}$ More recently, Moriguchi et al. ${ }^{62}$ found that alexithymic individuals showed less activation in the left caudal ACC, when viewing hands and feet depicted in painful situations. FeldmanHall et al. ${ }^{66}$ demonstrated that individuals with high levels of alexithymia have reduced neural activation within the Al when seeing others in pain, and are less motivated to act 

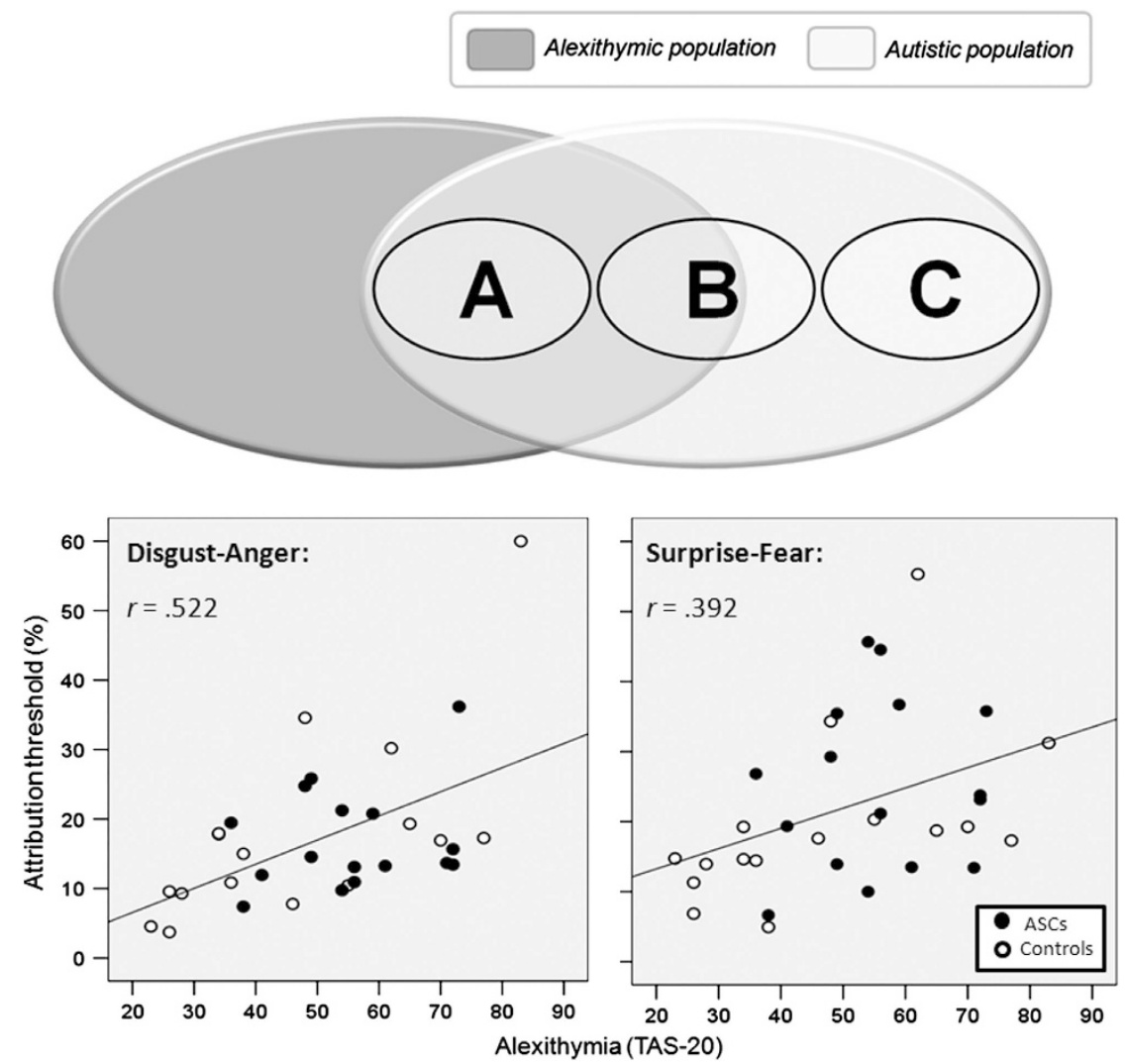

Figure 1 (Top panel) Illustration of the alexithymia hypothesis. Samples drawn from the autistic population may contain a high proportion of individuals with co-occurring alexithymia (for example, sample A), in which case the majority of tested individuals will exhibit emotional symptoms such as difficulties in recognizing others' emotions and reduced empathy. Samples may also contain relatively few individuals with co-occurring alexithymia (for example, sample C) yielding little evidence of emotional impairment in the majority of individuals tested, leading to the conclusion that autism is not characterized by emotional symptoms. More typically, however, samples drawn from the autistic population are likely to be heterogeneous; comprising a mix of individuals with varying degrees of co-occurring alexithymia (for example, sample B), leading to weak inconsistent trends toward emotional deficits across studies and wide heterogeneity within experimental samples. (Bottom panel) Representative data from Cook et al. ${ }^{76}$ demonstrating that increasing degrees of alexithymia is associated with increased attribution thresholds (indicative of poor emotion recognition) for emotional facial expressions. After accounting for alexithymia there was no effect of autism.

altruistically to relieve another's distress. Complimentary findings of structural differences within the AI and ACC have recently been revealed using voxel-based morphometry. ${ }^{73}$

The past two decades have seen growing acceptance that (1) alexithymia is associated with deficits of emotional experience, ${ }^{74,75}$ interpretation and recognition, ${ }^{64,69}$ and (2) that the incidence of severe alexithymia is substantially elevated in the autistic population. ${ }^{6,7}$ Nevertheless, studies of autism-even those investigating putative emotional symptoms-rarely use control groups matched for alexithymia, and typically fail to report the levels of alexithymia present in samples. This raises the very real possibility that, where observed, deficits of emotion recognition and empathy reflect disproportionate levels of alexithymia in autistic samples, rather than being characteristic of autism (Figure 1a). Support for the alexithymia hypothesis has been provided by a series of recent studies.

Emotion recognition. Several studies have recently investigated emotion recognition deficits, in individuals with and without autism, with varying degrees of alexithymia. ${ }^{76-78}$ In two psychophysical experiments, Cook et al. ${ }^{76}$ separately assessed the contribution of autism and alexithymia to difficulties of facial emotion recognition. In one experiment, participants were asked to assign an emotion label to morphed face stimuli expressing combinations of different emotions (two stimulus sets blended incrementally disgust and anger; happiness and fear). In a second experiment, participants simply had to identify whether sequentially presented expressions were identical. Alexithymia was found to be closely associated with imprecise recognition of emotion: although able to distinguish different facial expressions, individuals with severe alexithymia were unable to consistently label the emotions depicted (Figure 1b). Autism severity, however, did not correlate with any of the perceptual measures, nor was it associated with any deficit once differences in alexithymia were accounted for. (Neither autism nor alexithymia was predictive of identity recognition thresholds or performance on a sequential matching task, confirming that alexithymia is not associated with low-level visual impairments. Moreover, these findings accord with the view that atypical processing styles and deficits of low-level vision, associated with autism (reviewed by Simmons et al. ${ }^{79}$ ), often have negligible effects on tasks assessing the perception of faces. ${ }^{80}$ It remains an interesting possibility that autism is associated with disproportionately impaired memory for faces.) 
Using a similar paradigm, Heaton et al. ${ }^{77}$ investigated the relative contribution of autism and alexithymia to difficulties in recognizing vocal affect. Participants were asked to identify the emotion conveyed in verbal (three-digit numbers being read aloud) and nonverbal (for example, laughing, crying) vocalizations. Although recognition accuracy was reduced in the autistic group, further analyses revealed substantially elevated rates of alexithymia in the autistic sample and highly significant correlations $(r>0.60)$ between alexithymia scores and recognition accuracy. The authors concluded that, when differences in low-level vocal processing were taken into account, residual differences in emotion recognition accuracy were due to co-occurring alexithymia.

The contribution of alexithymia and autism to the recognition of musical affect has also been studied. ${ }^{78}$ Participants were presented with pieces of music and asked to indicate which of the 28 words described the emotional content. A group difference was identified; autistic participants chose fewer words, than matched controls, to describe the pieces. However, subsequent mediation analysis revealed that the effect was again because of co-occurring alexithymia: the presence of autism was no longer predictive of impoverished descriptions once alexithymia had been accounted for. In contrast, alexithymia continued to be a significant predictor once autism was accounted for.

Empathy. The contribution of alexithymia to the 'emotional symptoms of autism' is not only observed in behavior, but also in functional magnetic resonance imaging studies of empathic processes. ${ }^{81,82}$ Bird et al. ${ }^{81}$ measured the degree of neural activity evoked by a loved-one's pain, in those areas of the brain active when personally receiving pain, as an objective measure of empathy. Participants were again individuals with and without autism, with varying degrees of alexithymia. The authors observed that the degree of empathic brain activity in the Al was predicted by alexithymia in both autistic and nonautistic participants, and that once alexithymia was accounted for, there were no group differences in empathy related to autism.

A similar result was observed in a related study involving introspection upon emotion. ${ }^{82}$ Participants with and without autism and with varying degrees of alexithymia were asked to judge the emotion evoked in them by pictorial stimuli drawn from the International Affective Picture System ${ }^{83}$ including images of illness, death and injury, and to report their level of empathy. The process of judging one's emotional response to the distressing images resulted in significant Al activity, and the degree of this activity correlated with participants' selfreported degree of alexithymia and empathy.

\section{Implications}

Research methods and procedures. If correct, the alexithymia hypothesis has important implications for the methodology adopted in future studies of autism. When emotionrelated processes are investigated, studies should examine whether impairments are a primary feature of autism or a consequence of co-occurring alexithymia. Alexithymia is typically assessed using short self-report measures ${ }^{84,85}$ that may be completed in a few minutes. Matching autistic and control samples for alexithymia should therefore become as routine as matching for age, gender and IQ. Moreover, by ensuring that both autistic and control samples include individuals with varying degrees of alexithymia, ${ }^{76,81}$ the effect of the latter can be accurately quantified and, if necessary, controlled for statistically (that is, entered as a co-variate or partialled out in regression). Such designs also allow the investigation of interactions between alexithymia severity and autism.

In addition, extreme caution is required when interpreting the results of all studies of autism using 'emotional' stimuli (for example, emotional facial expressions), even those that purport to study 'non-emotional' processes (for example, 'Theory of Mind', language, imitation, mirroring). For example, the 'Reading the Mind in the Eyes Test' ${ }^{86,87}$ is frequently characterized as a measure of 'Theory of Mind' or 'mentalizing'. In this task, participants are presented with stimuli consisting of the eye regions of a face, and asked to infer the person's mental (for example, interested or disinterested?) and affective states (for example, relaxed or worried?). It is typically reported that individuals with autism tend to assign different states than typically developing individuals. However, because substantial proportions of the statements pertain to emotions, it is likely that co-occurring alexithymia will contribute to the poor performance of autistic samples. Accurate estimates of nonemotional deficits associated with autism thus require instruments that do not confound these abilities with emotion processing.

Clinical practice. If future research shows the alexithymia hypothesis to be correct, the diagnostic criteria for autism may require revision. If it is found that individuals with autism, but without alexithymia, exhibit no emotional impairments, problems of emotion processing (for example, a lack of empathy and impaired recognition of emotion in others) should no longer be considered diagnostic markers of autism. $^{1,2}$ The trend toward amalgamating the social and emotional symptoms of autism may need to be reversedunder our hypothesis social and emotional impairments should be viewed as distinct, with autism being associated with the former, but not the latter.

A greater appreciation of the association with alexithymia may also improve interventions for autism. Not only is alexithymia associated with a wide-range of emotional impairments, ${ }^{3,64,69}$ but it is also known to reduce the effectiveness of some therapies. ${ }^{88,89}$ The alexithymia hypothesis suggests the existence of subgroups within the autistic population, defined by the presence or absence of alexithymia. Given the ease with which alexithymia severity may be estimated using self-report instruments, intervention strategies could be tailored to meet the specific needs of each subgroup. Alternative approaches could thereby address the emotional problems of individuals with alexithymia, or build on the emotional competence of those autistic individuals without alexithymia to 'scaffold' social interaction.

\section{Future challenges}

Discussion of the alexithymia hypothesis brings into focus a number of outstanding questions and unresolved issues that 
demand further research attention. First, little is known about the origins and causes of alexithymia. Structural and functional neuroimaging have repeatedly implicated a number of regions, including the $\mathrm{Al}$ and $\mathrm{ACC}{ }^{62,65,66,72,73,81,82}$ Together, these areas constitute a neural circuit by which individuals are likely to become aware of, and reflect upon, their emotions. ${ }^{70,71}$ Weaker neural connectivity within this network, and between this network and higher-order sensory areas, may therefore result in difficulties in identifying one's own emotions and those of others. Nevertheless, further empirical work is needed to identify the etiology of alexithymia, particularly with respect to the contributions of genes and environment. The initial work being conducted in this area suggests both genetic and environmental contributions. ${ }^{90-94}$

A second, related, question concerns the substantially increased incidence of severe alexithymia in the autistic population. To date, little progress has been made in explaining this association. To offer some explanation, we speculate that (1) a genetic vulnerability to suboptimal neural connectivity may be a feature of several disorders; and (2) phenotypes characterized by particular cognitive and behavioral deficits reflect the locus of such poor connectivity. Where the affected networks relate principally to social cognition and cognitive control, a 'pure' autism phenotype may emerge. In contrast, a 'pure' alexithymic phenotype may result from suboptimal connectivity confined to limbic structures (for example, AI, ACC). More typically, however, poor connectivity may be diffuse across many of these networks-as a consequence of common genetic/environmental risk factors-resulting in the co-occurrence of autism and alexithymia. Although we can cite little evidence in support of this speculation, it is striking that weaker neural connectivity has been implicated in both autism ${ }^{95,96}$ and schizophrenia; ${ }^{97,98}$ another disorder associated with elevated rates of alexithymia.

A further challenge for future research is to identify objective measures of alexithymia. At present, self-report questionnaires are typically used to estimate symptom severity. These measures have the advantage of being quick to complete and have been shown to have predictive validity. Nevertheless, selfreport instruments are likely to underestimate levels of alexithymia in severely-affected individuals because of the fact that accurate reporting is likely to require a basic degree of emotional awareness. The use of self-report questionnaires may therefore underestimate the strength of the relationship between alexithymia and disordered emotion processing in certain clinical groups. It is important then that tools are developed to measure alexithymia that do not rely on accurate self-report or interoceptive awareness. Neuroimaging paradigms offer a potential solution, but remain costly and inefficient. Consequently, the use of other indices of physiological arousal, in addition to self-report, may offer a solution to this problem. Indeed, initial data suggest that the degree of trait alexithymia in autism, as measured by self-report questionnaires, correlates well with the degree of correspondence between objective measures of emotional arousal, as measured by galvanic skin response and heart-rate variability, and self-reported arousal. ${ }^{99}$ This technique validates the use of self-report questionnaires in the alexithymic population, does not require accurate selfreport, and provides a method for the detection of alexithymia even in the absence of awareness of emotional difficulties.
Finally, it also remains to be seen whether there are different subtypes of alexithymia. The inability to identify and describe emotions - the characteristic deficit of alexithymiamay arise from several neurocognitive impairments. Consequently, some authors have hypothesized the existence of two types of alexithymia: Type I, associated with reduced physiological arousal, and Type II, in which typical physiological arousal is present but disconnected from higher cognition. ${ }^{100,101}$ However, this position remains controversial and some have argued that a two-factor solution does not describe well the variance observed in the alexithymic population. ${ }^{102}$ Whether subtypes of alexithymia exist remains an open question, but one that must be addressed as a matter of priority.

\section{Extending the argument?}

In the foregoing sections, we have made a big claim that the deficits of emotional processing sometimes seen in autism are not a primary feature of this disorder, but are instead due to comorbid alexithymia. However, we have chosen to round off our review by alluding to an even bigger possibility: can cooccurring alexithymia also explain the emotional symptoms seen in other psychiatric disorders?

Elevated rates of alexithymia are seen in a number of disorders including schizophrenia, ${ }^{103,104}$ eating disorders, ${ }^{105,106}$ Parkinson's disease ${ }^{107,108}$ and social anxiety. ${ }^{109}$ Interestingly, deficits of emotional processing, including problems in recognizing the emotions of others, are also seen in many of these conditions (for example, Parkinson's Disease, ${ }^{110}$ Schizophrenia, ${ }^{111}$ alcohol abuse, ${ }^{112}$ eating disorders $^{113}$ and social anxiety ${ }^{114}$ ). Moreover, several of these conditions are characterized by atypical experience of emotion. For example, 'negative symptoms'-one of the five domains outlined in the diagnostic criteria for schizophrenia-consists of disordered emotional expression and diminished motivation and pleasure. ${ }^{1}$ These symptoms are supported by somewhat mixed empirical reports of atypical facial expression, emotion-related neural activity and emotional experience. ${ }^{115}$

To date, only a handful of studies have assessed the contribution of alexithymia to the emotional difficulties in disorders other than autism, but these generally support an extended alexithymia hypothesis. For example, Pedrosa Gil et al. ${ }^{116}$ found significant impairments of emotion recognition in patients with somatoform disorders. Crucially, however, this group deficit was no longer evident once alexithymia was accounted for statistically, suggesting that emotion recognition difficulties were due to elevated levels of alexithymia, and not somatoform disorder per se. Similarly, in a study of nonclinical individuals with a trend toward disordered eating, alexithymia severity was associated with emotion recognition difficulties over and above disordered eating symptomatology. ${ }^{117}$

\section{Conclusions}

In the present paper, we have advanced the view that the inconsistent emotional symptoms of autism, including a lack of empathy and problems of emotion recognition, are due to the substantially elevated incidence of severe alexithymia 
present in the autistic population, and not autism per se. This 'alexithymia hypothesis' is supported by a series of recent studies conducted on individuals with and without autism, and with varying degrees of alexithymia. In every case, whether behavioral studies of facial emotion recognition, ${ }^{76}$ recognition of vocal ${ }^{77}$ or musical affect, ${ }^{78}$ functional magnetic resonance imaging studies of empathy ${ }^{81}$ or emotional introspection, ${ }^{82}$ alexithymia, but not autism, has been associated with emotional deficits.

If proven correct, the alexithymia hypothesis has a number of substantive implications for autism research and clinical practice. Studies addressing emotion processing in autism should examine whether impairments are a primary feature of autism or a consequence of co-occurring alexithymia. Crucially, matching autistic and control samples for alexithymia should therefore become as routine as matching for age, gender and IQ. Caution is also required when interpreting the results of all studies of autism using 'emotional' stimuli, even those that purport to study 'non-emotional' processes; for example Theory of Mind or imitation. If it is found that individuals with autism, but without alexithymia, exhibit no emotional impairments, 'emotional symptoms' should no longer be considered diagnostic markers of autism.

Although an ever-increasing body of work is consistent with the alexithymia hypothesis, a number of key questions remain. Further empirical work is urgently needed to identify the etiology of alexithymia, particularly with respect to the contributions of genes and environment. A related question concerns the cause of the dramatically increased incidence of severe alexithymia in the autistic population and the potential role of genetic vulnerability to suboptimal neural connectivity. Finally, it remains to be seen whether an extended alexithymia hypothesis can explain the heterogeneity of emotional symptoms seen in other psychiatric disorders, such as schizophrenia and Parkinson's disease. Nevertheless, one thing is clear; this intriguing condition demands considerably more research attention than it currently receives.

\section{Conflict of interest}

The authors declare no conflict of interest.

Acknowledgements. We gratefully acknowledge the comments and advice of Rebecca Brewer, Jennifer Cook, Francesca Happé and Punit Shah on earlier drafts of the manuscript. GB was supported by a grant from the Baily Thomas Charitable Fund (3089/1).

1. APA. Diagnostic and Statisitcal Manual of Mental Disorders (DSM-V). American Psychiatric Association: Washington, DC, 2000.

2. Lord C, Risi S, Lambrecht L, Cook EH, Leventhal BL, DiLavore PC et al. The Autism Diagnostic Observation Schedule-Generic: a standard measure of social and communication deficits associated with the spectrum of autism. J Autism Dev Disord 2000; 30: 205-223.

3. Nemiah JC, Freyberger H, Sifneos PE. Alexithymia: a view of the psychosomatic process. In: Hill OW (ed) Modern Trends in Psychosomatic Medicine. Butterworths: London, 1976. pp 430-439.

4. Berthoz S, Pouga L, Wessa M. Alexithymia from the social neuroscience perspective. In: Decety J, Cacioppo J (eds) The Handbook of Social Neuroscience. Oxford University Press: Oxford, 2011.

5. Pellicano E, Stears M. Bridging autism, science and society: moving towards an ethicallyinformed approach to autism research. Autism Res 2011; 4: 271-282.

6. Berthoz S, Hill EL. The validity of using self-reports to assess emotion regulation abilities in adults with autism spectrum disorder. Eur Psychiatry 2005; 20: 291-298.
7. Hill E, Berthoz S, Frith U. Brief report: cognitive processing of own emotions in individuals with autistic spectrum disorder and in their relatives. J Autism Dev Disord 2004; 34: 229-235.

8. Piven J, Palmer P, Jacobi D, Childress D, Arndt S. Broader autism phenotype: evidence from a family history study of multiple-incidence autism families. Am J Psychiatry 1997; 154: $185-190$

9. Kanner L. Autistic disturbances of affective contact. Nervous Child 1943; 2: 217-250.

10. Asperger H. Die autistischen psychopathen im kindesalter. Eur Arch Psychiatry Clin Neurosci 1944; 117: 76-136.

11. Gaigg SB. The interplay between emotion and cognition in Autism Spectrum Disorder: implications for developmental theory. Front Integr Neurosci 2012; 6: 113.

12. Hobson RP. The autistic child's appraisal of expressions of emotion. J Child Psychol Psychiatry 1986; 27: 321-342.

13. Harms MB, Martin A, Wallace GL. Facial emotion recognition in autism spectrum disorders: a review of behavioral and neuroimaging studies. Neuropsychol Rev2010; 20: 290-322.

14. Begeer S, Koot HM, Rieffe C, Meerum Terwogt M, Stegge H. Emotional competence in children with autism: diagnostic criteria and empirical evidence. Dev Rev 2008; 28: 342-369.

15. Uljarevic M, Hamilton A. Recognition of emotions in autism: a formal meta-analysis. J Autism Dev Disord 2012; 43: 1517-1526.

16. Ashwin C, Chapman E, Colle L, Baron-Cohen S. Impaired recognition of negative basic emotions in autism: a test of the amygdala theory. Soc Neurosci 2006; 1: 349-363.

17. Humphreys K, Minshew N, Leonard GL, Behrmann M. A fine-grained analysis of facial expression processing in high-functioning adults with autism. Neuropsychologia 2007; 45: 685-695.

18. Wallace S, Coleman M, Bailey A. An investigation of basic facial expression recognition in autism spectrum disorders. Cogn Emot 2008; 22: 1353-1380.

19. Corden B, Chilvers R, Skuse D. Avoidance of emotionally arousing stimuli predicts socialperceptual impairment in Asperger's syndrome. Neuropsychologia 2008; 46: 137-147.

20. Lindner JL, Rosen LA. Decoding of emotion through facial expression, prosody and verbal content in children and adolescents with Asperger's syndrome. J Autism Dev Disord 2006; 36: 769-777.

21. Philip RCM, Whalley HC, Stanfield AC, Sprengelmeyer R, Santos IM, Young AW et al. Deficits in facial, body movement and vocal emotional processing in autism spectrum disorders. Psychol Med 2010; 40: 1919-1929.

22. Atkinson AP. Impaired recognition of emotions from body movements is associated with elevated motion coherence thresholds in autism spectrum disorders. Neuropsychologia 2009; 47: 3023-3029.

23. Hubert B, Wicker B, Moore DG, Monfardini E, Duverger H, Fonseca DD et al. Brief report: recognition of emotional and non-emotional biological motion in individuals with autistic spectrum disorders. J Autism Dev Disord 2007; 37: 1386-1392.

24. Allen R, Hill E, Heaton P. 'Hath charms to soothe...' An exploratory study of how high-functioning adults with ASD experience music. Autism 2009; 13: 21-41.

25. Hobson RP, Ouston J, Lee A. Emotion recognition in autism: coordinating faces and voices. Psychol Med 1988; 18: 911-923.

26. Piggot J, Kwon H, Mobbs D, Blasey C, Lotspeich L, Menon V et al. Emotional attribution in high-functioning individuals with autistic spectrum disorder: a functional imaging study. $J$ Am Acad Child Adolesc Psychiatry 2004; 43: 473-480.

27. Pelphrey KA, Morris JP, McCarthy G, LaBar KS. Perception of dynamic changes in facial affect and identity in autism. Soc Cogn Affect Neurosci 2007; 2: 140-149.

28. Ashwin C, Baron-Cohen S, Wheelwright S, O'Riordan M, Bullmore ET. Differential activation of the amygdala and the 'social brain' during fearful face-processing in Asperger Syndrome. Neuropsychologia 2007; 45: 2-14

29. Ozonoff S, Pennington BF, Rogers SJ. Are there emotion perception deficits in young autistic children? J Child Psychol Psychiatry 2006; 31: 343-361.

30. Castelli F. Understanding emotions from standardized facial expressions in autism and normal development. Autism 2005; 9: 428-449.

31. Adolphs R, Sears L, Piven J. Abnormal processing of social information from faces in autism. J Cogn Neurosci 2001; 13: 232-240.

32. Grossman RB, Bemis RH, Plesa Skwerer D, Tager-Flusberg H. Lexical and affective prosody in children with high-functioning autism. J Speech Lang Hear Res 2010; 53: 778-793.

33. Jones CRG, Pickles A, Falcaro M, Marsden AJS, Happe F, Scott SK et al. A multimodal approach to emotion recognition ability in autism spectrum disorders. J Child Psychol Psychiatry 2011; 52: 275-285.

34. O'Connor K. Brief report: impaired identification of discrepancies between expressive faces and voices in adults with Asperger's syndrome. J Autism Dev Disord 2007; 37: 2008-2013.

35. Gillberg CL. The Emanuel Miller Memorial Lecture 1991. J Child Psychol Psychiatry 2006; 33: 813-842.

36. Shamay-Tsoory SG, Tomer R, Yaniv S, Aharon-Peretz J. Empathy deficits in Asperger syndrome: a cognitive profile. Neurocase 2002; 8: 245-252.

37. Baron-Cohen $\mathrm{S}$, Wheelwright $\mathrm{S}$. The empathy quotient: an investigation of adults with Asperger syndrome or high functioning autism, and normal sex differences. J Autism Dev Disord 2004; 34: 163-175. 
38. Lombardo MV, Barnes JL, Wheelwright SJ, Baron-Cohen S. Self-referential cognition and empathy in autism. PLoS One 2007; 2: e883.

39. McIntosh DN, Reichmann, Decker A, Winkielman P, Wilbarger JL. When the social mirror breaks: deficits in automatic, but not voluntary, mimicry of emotional facial expressions in autism. Dev Sci 2006; 9: 295-302.

40. Minio-Paluello I, Baron-Cohen S, Avenanti A, Walsh V, Aglioti SM. Absence of embodied empathy during pain observation in Asperger syndrome. Biol Psychiatry 2009; 65: 55-62.

41. Premack D, Woodruff G. Does the chimpanzee have a theory of mind? Behav Brain Sci 1978; 1: 515-526.

42. Johnson SA, Filliter JH, Murphy RR. Discrepancies between self-and parent-perceptions of autistic traits and empathy in high functioning children and adolescents on the autism spectrum. J Autism Dev Disord 2009; 39: 1706-1714.

43. Davis MH. A multidimensional approach to individual differences in empathy. JSAS Catalogue of Selected Documents in Psychology 1980; 10: 85.

44. Yirmiya N, Sigman MD, Kasari C, Mundy P. Empathy and cognition in high-functioning children with autism. Child Dev 1992; 63: 150-160.

45. Greimel E, Schulte-Ruther M, Kircher T, Kamp-Becker I, Remschmidt H, Fink GR et al. Neural mechanisms of empathy in adolescents with autism spectrum disorder and their fathers. Neuroimage 2010; 49: 1055-1065.

46. Schulte-Ruther M, Greimel E, Markowitsch HJ, Kamp-Becker I, Remschmidt H, Fink GR et al. Dysfunctions in brain networks supporting empathy: an fMRI study in adults with autism spectrum disorders. Soc Neurosci 2011; 6: 1-21.

47. Dapretto M, Davies MS, Pfeifer JH, Scott AA, Sigman M, Bookheimer SY et al. Understanding emotions in others: mirror neuron dysfunction in children with autism spectrum disorders. Nat Neurosci 2005; 9: 28-30

48. Smith A. Emotional empathy in autism spectrum conditions: weak, intact, or heightened? J Autism Dev Disord 2009; 39: 1747-1748.

49. Dziobek I, Rogers K, Fleck S, Bahnemann M, Heekeren HR, Wolf OT et al. Dissociation of cognitive and emotional empathy in adults with Asperger syndrome using the Multifaceted Empathy Test (MET). J Autism Dev Disord 2008; 38: 464-473.

50. Rogers K, Dziobek I, Hassenstab J, Wolf OT, Convit A. Who cares? Revisiting empathy in Asperger syndrome. J Autism Dev Disord 2007; 37: 709-715.

51. Cohen-Rottenberg RB. Autism and empathy. http://autismandempathy.com, 2011

52. Capps L, Kasari C, Yirmiya N, Sigman M. Parental perception of emotional expressiveness in children with autism. J Consult Clin Psychol 1993; 61: 475

53. Press C, Richardson D, Bird G. Intact imitation of emotional facial actions in autism spectrum conditions. Neuropsychologia 2010; 48: 3291

54. Dimberg U, Thunberg M, Elmehed K. Unconscious facial reactions to emotional facial expressions. Psychol Sci 2000; 11: 86-89.

55. Bastiaansen JA, Thioux M, Nanetti L, van der Gaag C, Ketelaars C, Minderaa R et al. Age-related increase in inferior frontal gyrus activity and social functioning in autism spectrum disorder. Biol Psychiatry 2011; 69: 832-838.

56. Parker JD, Taylor GJ, Bagby RM. Alexithymia and the recognition of facial expressions of emotion. Psychother Psychosom 1993; 59: 197-202.

57. Parker PD, Prkachin KM, Prkachin GC. Processing of facial expressions of negative emotion in alexithymia: the influence of temporal constraint. J Pers 2005; 73: 1087-1107.

58. Prkachin GC, Casey C, Prkachin KM. Alexithymia and perception of facial expressions of emotion. Pers Individ Dif 2009; 46: 412-417.

59. Jessimer M, Markham R. Alexthymia: A right hemisphere dysfunction specific to recognition of certain facial expressions. Brain Cogn 1997; 34: 246-258.

60. Swart M, Kortekaas R, Aleman A. Dealing with feelings: characterization of trait alexithymia on emotion regulation strategies and cognitive-emotional processing. PLOS One 2009; 4: e5751.

61. McDonald PW, Prkachin KM. The expression and perception of facial emotion in alexithymia: a pilot study. Psychosom Med 1990; 52: 199-210.

62. Moriguchi Y, Decety J, Ohnishi T, Maeda M, Mori T, Nemoto K et al. Empathy and judging other's pain: an fMRI study of alexithymia. Cereb Cortex 2007; 17: 2223-2234.

63. Guttman H, Laporte L. Alexithymia, empathy, and psychological symptoms in a family context. Compr Psychiatry 2002; 43: 448-455.

64. Grynberg D, Luminet O, Corneille O, Grezes J, Berthoz S. Alexithymia in the interpersonal domain: a general deficit of empathy? Pers Individ Dif 2010; 49: 845-850.

65. Moriguchi Y, Ohnishi T, Lane RD, Maeda M, Mori T, Nemoto K et al. Impaired selfawareness and theory of mind: an fMRI study of mentalizing in alexithymia. Neuroimage 2006; 32: 1472-1482.

66. FeldmanHall O, Dalgleish T, Mobbs D. Alexithymia decreases altruism in real social decisions. Cortex 2012; 49: 899-904.

67. Bastiaansen J, Thioux M, Keysers C. Evidence for mirror systems in emotions. Phil Trans $R$ Soc B 2009; 364: 2391-2404.

68. Calder AJ, Lawrence AD, Young AW. Neuropsychology of fear and loathing. Nat Rev Neurosci 2001; 2: 352-363.

69. Lane RD, Ahern GL, Schwartz GE, Kaszniak AW. Is alexithymia the emotional equivalent of blindsight? Biol Psychiatry 1997; 42: 834-844.

70. Singer T, Critchley HD, Preuschoff K. A common role of insula in feelings, empathy and uncertainty. Trends Cogn Sci 2009; 13: 334-340.

71. Etkin A, Egner T, Kalisch R. Emotional processing in anterior cingulate and medial prefrontal cortex. Trends Cogn Sci 2011; 15: 85-93.
72. Kano M, Fukudo S, Gyoba J, Kamachi M, Tagawa M, Mochizuki H et al. Specific brain processing of facial expressions in people with alexithymia: an H215Oâ€ÿc§PET study. Brain 2003; 126: 1474-1484.

73. Ihme K, Dannlowski U, Lichev V, Stuhrmann A, Grotegerd D, Rosenberg N et al. Alexithymia is related to differences in gray matter volume: a voxel-based morphometry study. Brain Res 2012; 1491: 60-67.

74. Pollatos O, Gramann K. Electrophysiological evidence of early processing deficits in alexithymia. Biol Psychiatry 2011; 87: 113-121.

75. Pollatos O, Schubö A, Herbert BM, Matthias E, Schandry R. Deficits in early emotional reactivity in alexithymia. Psychophysiology 2008; 45: 839-846.

76. Cook R, Brewer R, Shah P, Bird G. Alexithymia, not autism, predicts poor recognition of emotional facial expressions. Psychol Sci 2013; 24: 723-732.

77. Heaton P, Reichenbacher L, Sauter D, Allen R, Scott S, Hill E. Measuring the effects of alexithymia on perception of emotional vocalizations in autistic spectrum disorder and typical development. Psychol Med 2012; 1: 1-7.

78. Allen R, Davis R, Hill E. The effects of autism and alexithymia on physiological and verbal responsiveness to music. J Autism Dev Disord 2013; 43: 432-444.

79. Simmons DR, Robertson AE, McKay LS, Toal E, McAleer P, Pollick FE. Vision in autism spectrum disorders. Vis Res 2009; 49: 2705-2739.

80. Weigelt $\mathrm{S}$, Koldewyn $\mathrm{K}$, Kanwisher $\mathrm{N}$. Face identity recognition in autism spectrum disorders: a review of behavioral studies. Neurosci Biobehav Rev 2012; 36: 1060-1084.

81. Bird G, Silani G, Brindley R, White S, Frith U, Singer T. Empathic brain responses in insula are modulated by levels of alexithymia but not autism. Brain 2010; 133: 1515-1525.

82. Silani G, Bird G, Brindley R, Singer T, Frith C, Frith U. Levels of emotional awareness and autism: an fMRI study. Soc Neurosci 2008; 3: 97-112.

83. Lang PJ, Bradley MM, Cuthbert BN. International Affective Picture System (IAPS): technical manual and affective ratings. The Center for Research in Psychophysiology, University of Florida: Gainesville, FL, 1999.

84. Bagby RM, Taylor GJ, Parker JD. The twenty-item Toronto Alexithymia Scale-II. Convergent, discriminant, and concurrent validity. J Psychosom Res 1994; 38: 33-40.

85. Vorst HCM, Bermond B. Validity and reliability of the Bermond-Vorst Alexithymia Questionnaire. Pers Individ Differ 2001; 30: 413-434.

86. Baron-Cohen S, Wheelwright S, Jolliffe T. Is there a 'language of the eyes'? Evidence from normal adults, and adults with autism or Asperger syndrome. Vis Cogn 1997; 4: 311-331.

87. Baron-Cohen S, Wheelwright S, Hill J, Raste Y, Plumb I. The 'Reading the mind in the eyes' test revised version: a study with normal adults, and adults with asperger syndrome or high-functioning autism. J Child Psychol Psychiatry 2001; 42: 241-251.

88. Loas G, Fremaux D, Otmani O, Lecercle C, Delahousse J. Is alexithymia a negative factor for maintaining abstinence? A follow-up study. Compr Psychiatry 1997; 38: 296-299.

89. Ogrodniczuk JS, Piper WE, Joyce AS. Effect of alexithymia on the process and outcome of psychotherapy: a programmatic review. Psychiatry Res 2011; 190: 43-48.

90. Baughman HM, Schwartz S, Schermer JA, Veselka L, Petrides KV, Vernon PA. A behavioral-genetic study of alexithymia and its relationships with trait emotional intelligence. Twin Res Hum Genet 2011; 14: 539-543.

91. Kano M, Mizuno T, Kawano Y, Aoki M, Kanazawa M, Fukudo S. Serotonin transporter gene promoter polymorphism and alexithymia. Neuropsychobiology 2012; 65: 76-82.

92. Picardi A, Fagnani C, Gigantesco A, Toccaceli V, Lega I, Stazi MA. Genetic influences on alexithymia and their relationship with depressive symptoms. J Psychosom Res 2011; 71: 256-263.

93. Walter NT, Montag C, Markett SA, Reuter M. Interaction effect of functional variants of the BDNF and DRD2/ANKK1 gene is associated with alexithymia in healthy human subjects. Psychosom Med 2011; 73: 23-28.

94. Allen R, Heaton P. Autism, music, and the therapeutic potential of music in alexithymia Music Percept 2010; 27: 251-261.

95. Geschwind DH, Levitt P. Autism spectrum disorders: developmental disconnection syndromes. Curr Opin Neurobiol 2007; 17: 103-111.

96. Frith $\mathrm{C}$. What do imaging studies tell us about the neural basis of autism. Novartis Found Symposium 2003; 251: 149-166.

97. Cook J, Barbalat G, Blakemore SJ. Top-down modulation of the perception of other people in schizophrenia and autism. Front Hum Neurosci 2012; 6: 175

98. Fitzsimmons J, Kubicki M, Shenton ME. Review of functional and anatomical brain connectivity findings in schizophrenia. Curr Opin Psychiatry 2013; 26: 172-187.

99. Gaigg S, Maurice A, Bird G. Objective test for Alexithymia supports the validity of selfreport measures. 2013 (in press)

100. Bermond B, Clayton K, Liberova A, Luminet O, Maruszewski T, Bitti PER et al. A cognitive and an affective dimension of alexithymia in six languages and seven populations. Cogn Emot 2007; 21: 1125-1136.

101. Vorst HCM, Bermond B. Validity and reliability of the Bermond-Vorst Alexithymia Questionnaire. Pers Individ Dif 2001; 30: 413-434.

102. Bagby RM, Quilty LC, Taylor GJ, Grabe HJ, Luminet O, Verissimo R et al. Are there subtypes of alexithymia? Pers Individ Dif 2009; 47: 413-418.

103. Van't Wout M, Aleman A, Bermond B, Kahn RS. No words for feelings: alexithymia in schizophrenia patients and first-degree relatives. Compr Psychiatry 2007; 48: 27-33.

104. Cedro A, Kokoszka A, Popiel A, Narkiewicz-Jodko W. Alexithymia in schizophrenia: an exploratory study. Psychol Rep 2001; 89: 95-98. 
105. Speranza M, Corcos M, Loas G, Stephan P, Guilbaud O, Perez-Diaz F et al. Depressive personality dimensions and alexithymia in eating disorders. Psychiatry Res 2005; 135: 153-163.

106. Speranza M, Loas G, Wallier J, Corcos M. Predictive value of alexithymia in patients with eating disorders: a 3-year prospective study. J Psychosom Res 2007; 63: 365-371.

107. Costa A, Peppe A, Carlesimo GA, Pasqualetti P, Caltagirone C. Alexithymia in Parkinson's disease is related to severity of depressive symptoms. Eur Neurol 2006; 13: 836-841.

108. Costa A, Peppe A, Carlesimo GA, Salamone G, Caltagirone C. Prevalence and characteristics of alexithymia in Parkinson's disease. Psychosomatics 2010; 51: 22-28.

109. Dalbudak E, Evren C, Aldemir S, Coskun KS, Yildirim FG, Ugurlu H. Alexithymia and personality in relation to social anxiety among university students. Psychiatry Res 2012; S0165-1781: 00783-00784.

110. Sprengelmeyer R, Young AW, Mahn K, Schroeder U, Woitalla D, Buttner T et al. Facial expression recognition in people with medicated and unmedicated Parkinson's disease. Neuropsychologia 2003; 41: 1047-1057.

111. Kohler CG, Bilker W, Hagendoorn M, Gur RE, Gur RC. Emotion recognition deficit in schizophrenia: association with symptomatology and cognition. Biol Psychiatry 2000; 48: $127-136$.

112. Kornreich C, Brevers D, Canivet D, Ermer E, Naranjo C, Constant E et al. Impaired processing of emotion in music, faces and voices supports a generalized emotional decoding deficit in alcoholism. Addiction 2012; 108: 80-88.
113. Oldershaw A, Hambrook D, Tchanturia K, Treasure J, Schmidt U. Emotional theory of mind and emotional awareness in recovered anorexia nervosa patients. Psychosom Med 2010; 72: 73-79.

114. Winton EC, Clark DM, Edelmann RJ. Social anxiety, fear of negative evaluation and the detection of negative emotion in others. Behav Res Ther 1995; 33 193-196.

115. Kring AM, Elis O. Emotion deficits in people with schizophrenia. Annu Rev Clin Psychol 2012; 9: 409-433.

116. Pedrosa Gil F, Ridout N, Kessler H, Neuffer M, Schoechlin C, Traue HC et al. Facial emotion recognition and alexithymia in adults with somatoform disorders. Depress Anxiety 2009; 26: E26-E33.

117. Ridout N, Thom C, Wallis DJ. Emotion recognition and alexithymia in females with nonclinical disordered eating. Eat Behav 2010; 11: 1-5.

(c) (i) $(9)$ Translational Psychiatry is an open-access journal published by Nature Publishing Group. This work is licensed under a Creative Commons Attribution-NonCommercialNoDerivs 3.0 Unported License. To view a copy of this license, visit http://creativecommons.org/licenses/by-nc-nd/3.0/ 